Sylwia Słowińska

Uniwersytet Zielonogórski

Hanna Solarczyk-Szwec

Uniwersytet Mikołaja Kopernika w Toruniu

\title{
Różnica w badaniach porównawczych na przykładzie projektu „Edukacja kulturalna dorosłych w Polsce i w Niemczech"
}

\author{
The difference in the comparative research \\ on the example of the project \\ "Cultural education of adults in Poland and Germany"
}

Streszczenie. Przedmiotem refleksji jest rola różnicy oraz podejście do niej w konceptualizacji i przeprowadzaniu badań porównawczych edukacji dorosłych na przykładzie realizowanego w latach 2000-2003 projektu „Edukacja kulturalna dorosłych w Polsce i w Niemczech”. Po 15 latach przyglądamy się edukacji kulturalnej dorosłych w Polsce powtórnie, by przez pryzmat kontynuowanych badań określić dynamikę różnic w badanym obszarze. W podsumowaniu odnosimy się do tego, co może być wartością dodaną badań porównawczych.

Słowa kluczowe: edukacja kulturalna dorosłych w Polsce i w Niemczech, podejście do różnicy w konceptualizacji badań porównawczych, wartość dodana badań porównawczych

Summary. The subject of the reflection is the role of difference and the approach to it in conceptualization and conduct comparative research of adult education on the example of the project "Cultural education of adults in Poland and Germany" wich was executed in years 2000-2003. After 15 years we look at the cultural education of adults in Poland once again in order to determine the dynamics of the differences on the examined area through the prism of the continued research. In the conclusion we refer to what can be the added value of comparative research.

Key words: adult cultural education in Poland and Germany, approach to the difference in conceptualization of comparative research, added value of the comparative research 


\section{Wprowadzenie}

Edukacja dorosłych jest tym sektorem oświaty, w którym jest najwięcej różnic w ujęciu porównawczym. Mają one różne źródła: kulturowe, społeczne i polityczne. Współcześnie dużą rolę odgrywają także uwarunkowania ekonomiczne - w większości krajów edukacja dorosłych jest dziś usługą na wolnym rynku, ze wszystkimi tego konsekwencjami dla jednostki i społeczeństwa. Badania porównawcze edukacji dorosłych są zatem dużym wyzwaniem dla badaczy, ponieważ z założenia muszą oni eksplorować różnice.

Jaką wartość możemy przypisać identyfikacji, analizowaniu i interpretowaniu różnic w badaniach porównawczych?

W pedagogice porównawczej tradycyjnie dużą rolę odgrywało odkrywanie i opisywanie ogólnych tendencji i kierunków rozwoju oświaty. To kierowało uwagę na poszukiwania zbieżności, wspólnych cech. Dostrzeganie podobieństw przychodzi z reguły łatwiej, duża jest też pokusa narzucania własnej optyki w ocenie badanych kwestii, co prowadzi także do eksponowania tego, co wspólne. Szukanie różnic, wrażliwość na różnice zapobiega natomiast pochopnym uogólnieniom, upraszczającym konkluzjom, inspiruje do szukania przyczyn zróżnicowania.

Odnosząc się do praktyki społecznej, różnica jest wartością w społeczeństwie o charakterze wspólnoty otwartej, co dalej skutkuje inkluzyjnym wzorem integracji społecznej (Tönnis 1988). W takim typie organizacji społecznej różnice nie są podstawą hierarchizacji, są postrzegane symbiotycznie, ponieważ wnoszą do wspólnoty inne, także deficytowe wartości, które wzbogacają wspólnotę. „Z taką wizją struktur społecznych koresponduje częściowo myśl postmodernistyczna głosząca, że charakterystycznym rysem współczesności jest zamiana znaczenia przypisywania różnicy, która staje się w coraz większym stopniu wartością samą w sobie” (Szumski 2006, s. 248).

Czy takie podejście do różnicy jest dziś aktualne?

Pod wpływem silnych ruchów migracyjnych w kierunku Europy wzrosło uznanie dla polityki narodowej, wrogiej wobec emigrantów, co prowadzi do budowania wspólnoty zamkniętej, gdzie różnorodność nie jest wartością. Towarzyszy temu upadek wartości demokratycznych i praw człowieka opartych na wolności. Skutkiem może być, wbrew rzeczywistym potrzebom, spadek zainteresowania badaniami porównawczymi, studiami międzykulturowymi, rozwijaniem koncepcji transkulturowych. Mieszanie się, przenikanie i hybrydyzacja to jednak niezaprzeczalne już cechy współczesnej kultury. Twórca koncepcji transkulturowości Wolfgang Welsch uważa, że tożsamość jest w dużej mierze zależna od „obcych” elementów, które umożliwiają wy- 
mianę stylów życia, wartości i przekonań. Kultury są maksymalnie ze sobą powiązane, a style życia nie kończą się na granicach kultur narodowych i idą dalej, znajdując podobny wydźwięk w innych kulturach (Welsch 1999). Tymczasem dziś w polityce i społeczeństwie obserwujemy przeciwstawne tendencje, które zaprzepaszczają dotychczasowy dorobek w dziedzinie integracji społecznej.

Zarysowany wyżej kontekst był dla autorek inspiracją do podjęcia rozważań nad rolą różnicy oraz podejściem do niej w konceptualizacji i przeprowadzaniu badań porównawczych edukacji dorosłych na przykładzie realizowanego w latach 2000-2003 projektu „Edukacja kulturalna dorosłych w Polsce i w Niemczech". Po 15 latach przyglądamy się edukacji kulturalnej dorosłych w Polsce powtórnie, by przez pryzmat kontynuowanych badań określić dynamikę różnic w badanym obszarze. W podsumowaniu odnosimy się do tego, co może być wartością dodaną badań porównawczych.

\section{Model konceptualizacji badań porównawczych edukacji dorosłych}

Wiedza oraz doświadczenia badaczy tworzą subiektywne warunki ramowe dla przedsięwzięć badawczych. Dotyczą one m.in. języka, schematów interpretacyjnych badaczy, metod zbierania i analizy danych wynikających z tradycji badawczych partnerów projektu. $\mathrm{W}$ badaniach międzynarodowych duże znaczenie mają historyczne i aktualne relacje między krajami partnerów projektu oraz związane z tym obiektywne warunki współpracy: polityka, prawo, finanse. Na przecięciu tych uwarunkowań powstaje lub nie powstaje wspólnota podzielanych interesów politycznych, społecznych, naukowych oraz zasad działania we wspólnocie. Wszystkie wymienione zmienne pozostają we wzajemnych związkach i relacjach między sobą, podlegając przemianom pod wpływem różnorakich czynników / warunków. Wieloletnia, długa współpraca między uczelniami, badaczami, ale przede wszystkim ciągłość zbudowana na kolejnych przedsięwzięciach naukowo-badawczych, oraz towarzyszące im bezpośrednie, trwałe, osobiste kontakty ułatwiają gotowość do dyskusji i porozumienie.

Realizacja projektów badawczych w obszarze edukacji dorosłych uwrażliwia na specyfikę badań porównawczych w tej dziedzinie. Na przykładzie projektu „Edukacja kulturalna dorosłych w Polsce i w Niemczech” można wskazać więcej różnic niż podobieństw między Polską i Niemcami w tej dziedzinie. Specyfika edukacji dorosłych prowadzić więc musi do postępowania 
badawczego, które nie redukuje różnorodności i różnic na drodze poszukiwania tego, co wspólne, aby przyczynić się do kreowania europejskiej wspólnoty. Temu służy równoprawność odmiennych teoretycznych i metodologicznych podejść wynikających ze specyfiki badań i praktyki edukacyjnej w poszczególnych krajach, aby na tej bazie w relacjach wypracować wspólną, elastyczną i otwartą strategię badań. Rys. 1. wizualizuje kluczowe kwestie na etapie konceptualizacji badań porównawczych edukacji dorosłych.

\section{Rys. 1. Konceptualizacja badań porównawczych edukacij dorostych}

Źródło: opracowanie wlasne.

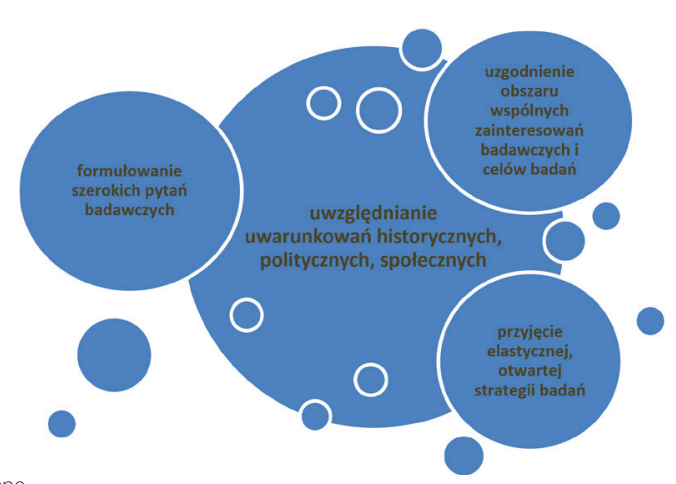

Punktem wyjścia jest ustalenie wspólnego obszaru zainteresowań badawczych umożliwiających szeroko rozumiane porównanie tak, aby nie stracić z pola widzenia uwarunkowań historycznych, politycznych i społecznych. Podejmowanie problemów ważnych dla wszystkich partnerów jest wstępnym warunkiem mentalnego zaangażowania partnerów w projekcie oraz podstawą refleksyjnej wymiany między partnerami na wszystkich etapach realizacji projektu. Ważną zasadą jest formułowanie szerokich problemów badawczych, aby mogła dojść do głosu różnorodność / odmienność problematyki badawczej ze względu na kraj, w którym są prowadzone badania. Takie podejście stwarza warunki do ciągłego różnicowania i konkretyzowania pytań oraz metodologii adekwatnie do sytuacji, czemu sprzyja przyjęcie elastycznej i otwartej strategii badań. Te same pytania nie muszą prowadzić do identycznych procedur badawczych, ale ważne jest, aby powstawały punkty przecięcia i obszary wspólne. W prezentowanym modelu badań porównawczych edukacji dorosłych czynności koncepcyjne i realizacja badań przenikają się. Nie są wyraźnie oddzielonymi w czasie, następują- 
cymi po sobie etapami pracy badawczej, lecz nakładają się na siebie. Pozwala to dopasować postępowanie badawcze do specyfiki edukacji dorosłych danego kraju, aby na tle innego kraju lepiej ją zrozumieć.

Poniżej prezentujemy przykład badań zrealizowanych zgodnie z opisanymi wyżej założeniami.

\section{O projekcie „Edukacja kulturalna dorosłych w Polsce i w Niemczech"}

Projekt „Edukacja kulturalna dorosłych w Polsce i w Niemczech” finansowany przez Federalne Ministerstwo Edukacji i Badań został zrealizowany w latach 2000-2003. W działania badawcze zaangażowane były zespoły naukowców z Uniwersytetu Humboldta w Berlinie (pod kierunkiem Wiltud Gieseke), Uniwersytetu Warszawskiego i Uniwersytetu Mikołaja Kopernika w Toruniu (pod kierunkiem Józefa Półturzyckiego) oraz Uniwersytetu Zielonogórskiego (pod kierunkiem Józefa Kargula). Opisywany projekt był kolejnym przedsięwzięciem badawczym w wieloletniej historii współpracy Uniwersytetu Warszawskiego i Uniwersytetu Humboldta w Berlinie (Depta, Półturzycki 2014).

W badaniach przeprowadzonych $\mathrm{w}$ ramach projektu skoncentrowano się na rozpoznaniu sytuacji edukacji kulturalnej dorosłych w Europie na przykładzie sąsiadujących regionów Polski i Niemiec, w drodze analiz regionalnych ofert edukacji kulturalnej, tj. Berlina i Brandenburgii oraz w Polsce: województwa lubuskiego, Warszawy i Płocka. W centrum zainteresowania usytuowano edukację kulturalną, zgodnie z przekonaniem, że eksploracja tego obszaru jest niezwykle istotna ze względu na jego znaczenie w kontekście integracji europejskiej. Edukacja kulturalna bowiem, jak pisze Wiltrud Gieseke, stanowi fundament międzynarodowych relacji (Gieseke i in. 2017). Edukacja kulturalna to istotny element edukacji całożyciowej. Ma pozytywne znaczenie dla samej jednostki, rozwoju jej osobowości, życia zawodowego i rodzinnego, a także wspiera uczestnictwo w kulturze danego kraju oraz zainteresowanie innymi kulturami. Stanowi ona część współczesnego stylu życia (Gieseke 2005, s. 13).

W badaniach poszukiwano informacji na temat typów instytucji realizujących edukację kulturalną, sposobu tworzenia programów i oferty, charakteru oferty, adresatów. Jednocześnie przyjęto elastyczne podejście, zgodnie z którym w miarę rozwoju procesu badawczego, ujawniającego różnice pomiędzy Polską a Niemcami w wymiarze politycznym, strukturalnym, kon- 
cepcji i adresatów edukacji kulturalnej, różnicowano i konkretyzowano procedurę badawczą. Zatem metodologia badań nie była identyczna w Polsce i w Niemczech, dostosowywano ją do specyfiki danego kraju. Fundamentalne znaczenie okazały się mieć przede wszystkim różnice w wymiarze polityczno-prawnym i strukturalnym. W Polsce w przeciwieństwie od Niemiec nie ma aktów prawnych regulujących kwestię edukacji dorosłych, oba kraje różnią typy i charakter funkcjonujących $w$ nich instytucji oraz organizacji edukacji dorosłych. W Niemczech istnieje gęsta sieć uniwersytetów powszechnych (VHS, HVHS), ewangelickich i katolickich ośrodków edukacji, centrów edukacji kobiet, Uranii - towarzystwa edukacji dorosłych. Tworzą one bogatą i urozmaiconą ofertę edukacji kulturalnej dla osób dorosłych. Oferta ta opisana jest w systematycznie wydawanych, szczegółowych oraz archiwizowanych programach i to właśnie analiza programów, traktowanych jako manifestacja sposobu myślenia o edukacji kulturalnej, wyraz jej koncepcji, była podstawową metodą niemieckiego zespołu badawczego. Dodatkowo w Niemczech zastosowano analizę regionalną edukacji kulturalnej „dodatkowej“" (beigeordnete kulturelle Bildung), czyli oferty instytucji, dla

Postępowanie w badaniach empirycznych edukacji kulturalnej dorosłych w Berlinie i Brandenburgii

\begin{tabular}{|c|c|c|c|}
\hline Analiza programów & Analiza regionalna & $\begin{array}{l}\text { Analiza przypadku } \\
\quad \text { (instytucja edukacji dorosłych) }\end{array}$ & Analiza dziedzin \\
\hline $\begin{array}{l}\text { Instytucje edukacji dorosłych } \\
\text { (archiwum programów) }\end{array}$ & Edukacja dodatkowa & $\begin{array}{l}\text { Uniwersytet Powszechny Dahme- } \\
\text { conmonumold }\end{array}$ & $\begin{array}{l}\text { Praktyka kulturalna / } \\
\text { aktywność } \\
\text { kulturalna }\end{array}$ \\
\hline $\begin{array}{l}\text { Ilościowa analiza danych z lat } \\
1996 \text { i } 2001 \text { z } \\
47 \text { uniwersytetów powszechnych } \\
18 \text { ewangelickich ośrodków }\end{array}$ & $\begin{array}{l}\text { Region Uckermark } \\
\text { Region Berlin } \\
\text { Friedrichshain - } \\
\text { Kreuzberg }\end{array}$ & $\begin{array}{l}\text { Analiza przypadku } \\
\text { (edukacja kulturalna dodatkowa) } \\
\text { Akademia Muzeów Państwowych w } \\
\text { Berlinie }\end{array}$ & $\begin{array}{l}17 \text { wywiadów } \\
\text { eksperckich }\end{array}$ \\
\hline $\begin{array}{l}\text { edukacji } \\
4 \text { katolickich ośrodków edukacji } \\
\text { dorosłych } \\
15 \text { centrów kobiet }\end{array}$ & $\begin{array}{l}19 \text { wywiadów } \\
\text { eksperckich }\end{array}$ & $\begin{array}{l}\text { Analiza przypadku } \\
\text { (centrum socjolkulturalne) } \\
\text { Centrum Kobiet Cottbus }\end{array}$ & \\
\hline $\begin{array}{l}6 \text { Uranii } \\
\text { oraz ich interpretacja } \\
13 \text { wywiadów zogniskowanych } \\
\text { Z przedstawicielami instytucji }\end{array}$ & & $\begin{array}{l}\text { Analiza przypadku } \\
\text { (edukacja kulturalna dodatkowa) } \\
\text { Kulturhaus Altes Rathaus Potsdam }\end{array}$ & \\
\hline
\end{tabular}

Źródło: Gieseke W., Opelt K (2005), Methodisches Vorgehen der Gesamtuntersuchung, [w:] W. Gieseke, K Opelt, H. Stock, I. Börjesson, I. (red.), Kulturelle Enwachsenenbildung in Deutschland. Exemplarische Analyse Berlin/Brandenburg, Münster, s. 40. 
których edukacja kulturalna nie jest zadaniem podstawowym; studia przypadku instytucjonalnych form edukacji kulturalnej oraz analizę "dziedzin” (Spartenanalyse) edukacji kulturalnej związanej ze stowarzyszeniami, skoncentrowanej na konkretnej dziedzinie kultury symbolicznej, np. muzyce, tańcu itd. (zob. Gieseke, Opelt 2005, s. 39).

Z kolei w Polsce niemożliwe okazało się potraktowanie programów instytucji edukacji dorosłych jako głównego źródła danych. Tu bowiem sieć podmiotów edukacji dorosłych nie była i nie jest aż tak mocno rozwinięta, a przede wszystkim, te najważniejsze instytucje oraz organizacje koncentrują się na edukacji dalszej zawodowej (CKU - Centrum Kształcenia Ustawicznego, ZDZ - Zakład Doskonalenia Zawodowego, TWP - Towarzystwo Wiedzy Powszechnej, ODN - Ośrodek Doskonalenia Nauczycieli). Wyjątek stanowią nieliczne w Polsce uniwersytety ludowe, a przede wszystkim uniwersytety trzeciego wieku, dla których edukacja kulturalna seniorów to zadanie podstawowe. $\mathrm{W}$ związku $\mathrm{z}$ tym $\mathrm{w}$ naszym kraju prowadzenie edukacji kulturalnej (dla wszystkich grup wiekowych) przypada przede wszystkim instytucjom kultury. Zajmują się tym głównie domy kultury, dla których jest to jedno z zadań statutowych, równie ważne jak organizowanie imprez kulturalnych, form amatorskiej twórczości artystycznej czy spędzania czasu wolnego dzieci i młodzieży. Zatem rodzimą specyfiką jest, iż ofertę taką tworzą przede wszystkim instytucje kultury i to głównie one zostały objęte badaniami. Ponadto istotną różnicą decydującą o tym, że postępowanie badawcze na terenie Polski przebiegało odmiennie, był charakter i forma programów instytucji oferujących edukację kulturalną. W przeciwieństwie do realiów niemieckich tu mają one najczęściej kształt lapidarnych harmonogramów lub ulotek i nie są archiwizowane. Zatem koniecznym stało się dostosowanie metody zbierania danych do tych uwarunkowań. Wprawdzie przeprowadzona została również analiza programów instytucji kultury oraz edukacji dorosłych, ale najważniejszą rolę odegrały wywiady z przedstawicielami tych podmiotów. Dodatkowo zastosowano też badania ankietowe w placówkach kulturalnych i oświatowych; studium przypadku instytucjonalnych form edukacji kulturalnej (zob. Kargul, Börjesson 2005; Depta i in. 2004; Kargul i in. 2004).

W obu krajach natomiast dla części stowarzyszeń społeczno-kulturalnych i instytucji kultury, takich jak muzea, biblioteki, galerie, teatry, edukacja kulturalna stanowi sferę działalności dodatkowej (beigeordnete kulturelle Bildung). Podmioty te realizują ją obok głównego nurtu działań, związanego z profilem ich działalności i czynią to w sposób systematyczny, jak i sporadycznie. Zarówno w Polsce jak i w Niemczech funkcjonują także podmioty, 
Rys. 3.

\begin{tabular}{|c|c|c|}
\hline \multicolumn{3}{|c|}{$\begin{array}{l}\text { Postępowanie w badaniach empirycznych edukacji kulturalnej dorosłych w woj. lubuskim, Płocku, } \\
\text { Warszawie }\end{array}$} \\
\hline Lubuskie & Płock & Warszawa \\
\hline $\begin{array}{l}\text { Analiza programów instytucji kultury i } \\
\text { instytucji edukacji dorostych: }\end{array}$ & $\begin{array}{l}\text { Badania ankietowe } \mathrm{v} \\
22 \text { instytucjach kultury: }\end{array}$ & $\begin{array}{l}\text { Badania ankietowe w } 56 \\
\text { instytucjach: }\end{array}$ \\
\hline 50 domów kultury & 6 domów kultury & 14 domów kultury \\
\hline 24 stowarzyszenia & 5 stowarzyszeń & 18 muzeów i galerii \\
\hline 4 muzea & 3 biblioteki & 8 bibliotek \\
\hline 2 biblioteki & 3 muzea & 5 teatrów \\
\hline 2 galerie & $\begin{array}{l}1 \text { teatr } \\
2 \text { zespoły artystyczne }\end{array}$ & $\begin{array}{l}11 \text { innych (stowarzyszenia, fundacje, } \\
\text { placówki przykościelne, prywatne) }\end{array}$ \\
\hline Wywiady zogniskowane & 1 szkoła muzyczna & \\
\hline $\begin{array}{l}\text { Z przedstawicielami (kierownikami) } \\
\text { instytucji kultury i instytucji edukacji: }\end{array}$ & 1 galeria & $\begin{array}{l}\text { Studia przypadku } \\
9 \text { instytucji: }\end{array}$ \\
\hline $\begin{array}{l}37 \text { z kierownikami } \\
\text { domów kultury } \\
\text { (edukacja kulturalna jako jedno z } \\
\text { równorzędnych zadań instytucji) }\end{array}$ & $\begin{array}{l}21 \text { instytucji: } \\
6 \text { domów kultury (edukacja kulturalna } \\
\text { jako jedno z równorzędnych zadań }\end{array}$ & $\begin{array}{l}3 \text { domy kultury (edukacja kulturalna } \\
\text { jako jedno z równorzędnych zadań } \\
\text { instytucji) }\end{array}$ \\
\hline $\begin{array}{l}7 \text { z prezesami uniwersytetów trzeciego } \\
\text { wieku (edukacja kulturalna dorosłych } \\
\text { jako podstawowe zadanie) }\end{array}$ & $\begin{array}{l}\text { instytucji) } \\
3 \text { biblioteki, } 3 \text { muzea, } 1 \text { teatr, } 1 \text { galeria, } \\
2 \text { parafie, } 3 \text { stowarzyszenia (edukacja } \\
\text { kulturalna jako zadanie dodatkowe) }\end{array}$ & $\begin{array}{l}2 \text { galerie, } 2 \text { muzea (edukacja } \\
\text { kulturalna jako zadanie dodatkowe); } \\
2 \text { uniwersytety trzeciego wieku } \\
\text { (edukacja kulturalna dorosłych jako }\end{array}$ \\
\hline
\end{tabular}

Żródło: opracowanie własne.

oferujące ludziom dorosłym możliwość długotrwałego uprawiania określonej dziedziny artystycznej, np. muzyki, tańca, teatru, malarstwa / rysunku. Definiują one swoją ofertę jako praktykę kulturalną (kulturelle Praxis), z nią jednak zawsze nieodłącznie wiąże się też edukacja. Mieszczą się tu działające w obu krajach stowarzyszenia koncentrujące się na określonej dziedzinie artystycznej, szkoły tańca, muzyczne i in. (zob. Stock 2005).

Analiza programów edukacji kulturalnej oraz analizy działalności instytucji edukacji dorosłych, instytucji kultury oraz stowarzyszeń społeczno-kulturalnych ujawniły szerokie spektrum ofert. Badania pozwoliły też stwierdzić, że w obu krajach dostęp do edukacji kulturalnej tworzą trzy portale (trzy rodzaje ofert - trzy rodzaje dostępu do kultury): receptywny, kreatywny oraz komunikacyjny, inaczej interkulturowy (zob. Gieseke 2005, s. 14). W Polsce, podobnie jak w Niemczech, dominuje oferta o charakterze kreatywnym - zakładająca aktywny, twórczy udział w zajęciach. Wśród najpopularniejszych dziedzin, których dotyczą te zajęcia, w Niemczech znalazły się malarstwo / rysunek oraz taniec, a w Polsce - muzyka, śpiew, te- 
atr. Z kolei w ramach oferty aktywności receptywnej najliczniejszą grupę w Polsce stanowią te, które dotyczą historii sztuki i wiedzy kulturoznawczej, a także literatury oraz zajęcia interdyscyplinarne. W Niemczech połowa oferty koncentruje się na historii kultury, popularnością choć znacznie mniejszą, cieszy się też literatura i religia. W obu krajach najmniej ofert edukacji kulturalnej wpisuje się w trzeci rodzaj: komunikacyjny / interkulturowy. I w Polsce, i w Niemczech zajęcia mają charakter zdarzeń cyklicznych, jak i jednorazowych. Dominacja oferty aktywności twórczej przekłada się na popularność określonych form i metod pracy. W Polsce są zatem to najczęściej sekcje i koła zainteresowań, formy należące do „żelaznego repertuaru” polskich domów kultury, mniej popularne okazały się warsztaty i projekty. Natomiast w Niemczech połowę ofert stanowiły kursy - forma, która z kolei nierozerwalnie wiąże się z uniwersytetami powszechnymi (VHS), dalej sytuują się wykłady i wycieczki, za nimi zaś dopiero warsztaty. Jak zatem pokazały badania, preferowane formy i metody pracy są związane z profilem i typem instytucji, a także ich tradycją.

Kolejny wymiar edukacji kulturalnej, w ramach którego zidentyfikowano znaczące różnice pomiędzy oboma krajami, dotyczy adresatów oferty. Zarówno w obszarze refleksji naukowej, jak i w sferze praktyki w Polsce edukacja kulturalna tradycyjnie wiązana była z dziećmi i młodzieżą. Być może jest to jedna z ważniejszych przyczyn, dla których nie zajmują się nią polskie instytucje i organizacje edukacji dorosłych (poza UTW). Niewątpliwie do przeobrażenia w myśleniu o uczestnikach edukacji kulturalnej przyczyniło się upowszechnianie się w Polsce od końca lat 90. szerokiego pojmowania edukacji jako procesu całożyciowego. Jednak, jak pokazały badania, w sferze praktyki nadal można odnaleźć tradycyjne myślenie o adresatach edukacji kulturalnej. Instytucje kultury orientują bowiem większość swoich ofert edukacji kulturalnej na młodsze grupy wiekowe, zaś zmiana myślenia o adresatach ujawnia się w poszerzeniu ich kręgu o seniorów. Tak więc edukacja kulturalna w Polsce kierowana jest zasadniczo do trzech grup wiekowych: dzieci, młodzieży, osób starszych. Zdecydowanie poza sferą zainteresowania pozostają dorośli w średnim wieku. Inaczej sytuacja wygląda w Niemczech, gdzie ofertę edukacji kulturalnej dla dorosłych tworzą przede wszystkim instytucje edukacji dorosłych. Większość tej oferty (75\%) jest adresowana do wszystkich dorosłych, zaś pozostałe orientują się na specyficzne grupy uczestników: np. kobiety, samotnych rodziców, seniorów, małżeństwa, osoby z niepełnosprawnością, obcokrajowców i in.

Zidentyfikowane w badaniach różnice w edukacji kulturalnej dorosłych w Polsce i w Niemczech po 15 latach są nadal aktualne, przede wszystkim ze 
względu na to, iż ich źródła tkwią bardzo głęboko: dotyczą tradycji, uwarunkowań prawno-finansowych i instytucjonalnych.

Jak pokazał omawiany projekt, diametralne różnice w wymiarze strukturalnym edukacji kulturalnej dorosłych pomiędzy oboma krajami, nie uniemożliwiają porównania. Identyczne struktury instytucjonalne bowiem nie muszą stanowić punktu wyjścia badań porównawczych. Różnice, trafnie rozpoznane już na początkowym etapie działań, pozwalają nadać odpowiedni kształt postępowaniu badawczemu, a przez to ujawniać kolejne rozbieżności, interpretować je oraz zrozumieć, a także odkrywać punkty styczne. W projekcie „Edukacja kulturalna dorosłych...” oprócz wielu znaczących różnic zidentyfikowano więc także istotne podobieństwa, przede wszystkim wspomniane trzy portale edukacji kulturalnej, ofertę edukacji kulturalnej dodatkowej i ofertę „dziedzin” (Sparten).

Tak realizowane badania koncentrujące się na różnicach i odnajdujące punkty styczne umożliwiły refleksyjną wymianę i zrozumienie zjawiska edukacji kulturalnej dorosłych w perspektywie międzynarodowej, sprzyjającej wzajemnemu uczeniu się w dziedzinie politycznej, społecznej i zawodowej. Bowiem, jak wskazuje Wiltrud Gieseke, w omawianym projekcie „Nie chodziło o ewaluację, lecz o odkrycie punktów zaczepienia dla interkulturowej współpracy w ramach edukacji kulturalnej. Badania pokazały obszary, w których oba kraje mogą się od siebie wzajemnie uczyć" (Gieseke i in. 2005, s. 15).

\section{Trwałość i kontynuacja}

Znaczenie i wartość projektu badawczego wiąże się ściśle z jego trwałością, żywotnością odkryć i wniosków, obecnością wyników w dyskursie naukowym, zdolnością do inspirowania dyskusji i odniesień, czyli siłą oddziaływania. Trwałość projektu zapewniają nie tylko różnego rodzaju formy upowszechniania wyników, dziś znacznie wzbogacone dzięki wykorzystaniu internetu, ale także następujące po nich nowe przedsięwzięcia (projekty badawcze, publikacje, seminaria), które kontynuują badania, nawiązują do nich, wykorzystują wyniki w różny sposób. Projekt „Edukacja kulturalna dorosłych w Polsce i w Niemczech" stwarzał szerokie możliwości kontynuowania badań, ich powtarzania zarówno wspólnie - w kooperacji międzynarodowej, jak i oddzielnie.

Badania przeprowadzone w ramach projektu „Edukacja kulturalna dorosłych..." miały swoją kontynuację na przestrzeni ostatnich lat w obu kra- 
jach. Owocem tych działań jest m.in. monografia przygotowana przez Wiltrud Gieseke, Marion Fleige i Steffi Robak Kulturelle Erwachsenenbildung. Strukturen - Partizipationsformen - Domänen (2015), w której autorki wykorzystały wyniki omawianych badań porównawczych, a także projektów nawiązujących do nich, które dotyczyły: edukacji międzykulturowej, treści pozaformalnej edukacji kulturalnej dorosłych i młodzieży oraz oferty uczenia się dorosłych w muzeach. Ciągłość badań konstytuuje także oparcie się w monografii na koncepcji trzech portali edukacji kulturalnej dorosłych autorstwa Wiltrud Gieseke, wypracowanej w ramach projektu polsko-niemieckiego, a szczególną wartość stanowi tu poszerzenie tej koncepcji o nowy portal zidentyfikowany $\mathrm{w}$ kolejnych badaniach - portal transkulturowy (Słowińska 2016). W Polsce zaś kontynuację badań porównawczych edukacji kulturalnej dorosłych stanowiły m.in. przedsięwzięcia Sylwii Słowińskiej. Po pierwsze należy tu wymienić badania nad polskimi i niemieckimi koncepcjami edukacji kulturalnej (Słowińska 2007). Po drugie dopełnieniem eksploracji podjętych na użytek polsko-niemieckiego projektu, w którym koncentrowano się głównie na edukacji ulokowanej w instytucjach kultury były badania „Inicjatywy i ludzie w kulturze lubuskiej - nowe przestrzenie” (2012), w których zespół z Uniwersytetu Zielonogórskiego pod kierunkiem Sylwii Słowińskiej skupił się na rozpoznaniu inicjatyw kulturalnych ulokowanych poza ramami tradycyjnych instytucji kultury i oświaty (Słowińska i in. 2012; Słowińska 2017). Po trzecie, zainteresowania badawcze tematyką edukacji kulturalnej dorosłych dalej realizowane były w projekcie „Inicjatywy z udziałem osób 50+ a rozwój kapitału społecznego w woj. lubuskim diagnoza i ewaluacja" (Słowińska 2014).

Wyniki tych badań oraz innych przedsięwzięć przeprowadzonych w ostatnich latach w Polsce pokazały, że obszar edukacji kulturalnej jawi się jako niezwykle dynamiczny i zróżnicowany, podlega ciągłym zmianom, wywoływanym pod wpływem czynników politycznych, ekonomicznych, społeczno-kulturowych. Zmiany, jakie dokonały się od zakończenia badań polsko-niemieckich, mają charakter rozwojowy. Istotne przeobrażenia uwidaczniają się przede wszystkim w wymiarze strukturalnym. Po pierwsze zatem silnemu wzrostowi ulegała ilość organizacji pozarządowych (stowarzyszeń), które stają się coraz bardziej znaczącym podmiotem oferującym edukację kulturalną. Ich rozwój wiąże się z postępującym w Polsce po 1989 procesem budowania społeczeństwa obywatelskiego, jest też stymulowany odgórnie przez programy dotacyjne, oferujące tego typu podmiotom dofinansowanie projektów. Po drugie, w ostatnich 15 latach silniej zaznaczyły swą obecność w edukacji kulturalnej podmioty komercyjne, takie jak szko- 
ły tańca, gotowania, muzyczne, różnego rodzaju firmy tworzące odpłatną ofertę aktywności artystycznej i edukacji kulturalnej. Tym procesom towarzyszą zmiany w obszarze metodycznej aranżacji edukacji kulturalnej. Pod wpływem finansowania rośnie intensywnie ilość działań w formie projektów. Z kolei rozwój komercyjnej oferty przyczynia się do wzrostu popularności kursów i warsztatów. Na podstawie badań realizowanych w ostatnich latach w Polsce można wnioskować, że najmniej przeobrażeń dokonuje się w wymiarze adresatów edukacji kulturalnej. Analizy wniosków o dofinansowanie projektów w ramach programu MKiDN Edukacja kulturalna pokazują, że są nimi nadal przede wszystkim młodzież i dzieci (Krajewski, Schmidt 2014). $Z$ drugiej strony programy dotacyjne zorientowane na aktywizacje ludzi starszych w istotnym stopniu przyczyniły się do tego, że silnie rozwinęła się oferta edukacji kulturalnej dla seniorów (Słowińska 2015). Tę ofertę, niezależnie od dofinansowania rozbudowują dynamicznie rozwijające się uniwersytety trzeciego wieku, pokrywające Polskę coraz gęstszą siecią.

Przeobrażenia dokonują się także w sferze pojmowania kultury i edukacji kulturalnej. Zauważalna staje się tendencja do odchodzenia od wąskiego, wartościującego pojmowania kultury i przejście ku rozumieniu antropologicznemu, lub inspirowanemu stanowiskiem antropologicznym. To przekłada się na poszerzenie spektrum dziedzin, których dotyczy oferta edukacji kulturalnej, jej zadań, a także prowadzi do rezygnacji z hierarchicznego i oceniającego podejścia do edukacji.

Wciąż zatem w obszarze edukacji kulturalnej dorosłych w obu krajach kształtują się nowe zjawiska, pojawiają się odmienne tendencje i konstytuują się kolejne punkty styczne. Przeobrażenia te kreują zatem potrzebę ciągłego monitorowania tego zróżnicowanego obszaru i inspirują do kontynuowania jego eksploracji.

\section{Podsumowanie}

Zaprezentowany model badań porównawczych edukacji dorosłych, gdzie różnice odgrywają istotną rolę na każdym etapie badania, jest możliwy dzięki podejściu relacyjnemu, tj. uwzględnianiu sieci związków na różnych poziomach, wyrastających z przeszłości, na bieżąco weryfikowanych, jak i tworzonych w trakcie realizacji projektu. Podstawą relacyjności jest gotowość do wymiany, która jest okazją do konfrontacji z różnorodnością oraz do dialogu, w którym nie ma hierarchii. „Wymiana, uzgodnienie i rozumienie uczestniczących jednostek sprzyjają rozwojowi" (Gieseke 2007, s. 225) nie tylko 
w wymiarze indywidualnym, ale także społecznym, a poprzez badania porównawcze - także międzynarodowym.

Realizacja badań międzynarodowych przynosi nie tylko rezultaty w postaci wiedzy odpowiadającej na postawione pytania badawcze. Współpraca taka jest także źródłem dodatkowych korzyści, zarówno w wymiarze indywidualnym, jak i w odniesieniu do środowisk naukowych oraz wspólnoty międzynarodowej. Wspólne badania jako płaszczyzna wymiany naukowej tworzą przede wszystkim sieć kontaktów, budują w ten sposób podstawy dalszej współpracy i tworzą warunki dla jej rozwoju, poszerzania i umacniania. To także przestrzeń osobistego rozwoju badaczy, wzajemnego uczenia się i inspirowania. Nie do przecenienia są tu również korzyści związane z międzykulturowym uczeniem się stanowiącym podstawę procesów budowania wspólnoty międzynarodowej, która wymaga autentycznej współpracy w obrębie swoich dziedzin i nieograniczania się do wizyt oraz niezobowiązującej wymiany. Chodzi zatem o realizację konkretnych przedsięwzięć, które sprzyjają wytwarzaniu się transkulturowej praktyki badawczej, umożliwiają społeczne i demokratyczne uczenie się, pomnażają wiedzę na temat aktualnej sytuacji w krajach partnerów oraz poszerzają kompetencje historyczne, kulturowe, językowe, które można wykorzystać do budowania międzynarodowej wspólnoty.

\section{Bibliografia}

Depta H., Półturzycki J., Solarczyk H. (red.) (2004), Edukacja kulturalna dorosłych. Raport z badań międzykulturowych, Wyd. ITEE, Warszawa-Płock.

Depta H., Półturzycki J. (2014), Ćwierć wieku wspótpracy naukowej między Wydziałem Pedagogicznym UW a Zakładem Pedagogiki Szkoły Wyższej oraz Instytutem Edukacji Dorostych Uniwersytetu Humboldta w Berlinie, „ Kwartalnik Pedagogiczny" 4.

Depta H., Półturzycki J., Solarczyk H. (red.) (2004), Edukacja kulturalna dorosłych: raporty z badań międzykulturowych, Wyd. ITEE, Warszawa-Płock.

Fleige M., Gieske W., Robak S. (2015), Kulturelle Erwachsenenbildung: Strukturen Partizipationsformen - Domänen, Bertelsmann Verlag, Bielefeld.

Gieseke W., Kargul J. (red.) (2005), Europäisierung durch kulturelle Bildung. Bildung - Praxis - Event:

- Vol. 1: Gieseke W., Opelt K., Stock H., Börjesson I., Kulturelle Ewachsenenbildung in Deutschland - Exemplarische Analyse Berlin/ Brandenburg, Waxmann Verlag, Münster; 
- Vol 2: Depta H., Kargul J., Półturzycki J. (red.), Kulturelle Erwachsenenbildung in Polen am Beispiel Lubuskie, Warschau und Płock, Waxmann Verlaf, Münster;

- Vol 3: Deutsch-polnische Forschergruppe (red.), Interkulturelle Betrachtungen kultureller Bildung in Grenzregion - mit Buckower Empfehlungen, Berlin Humboldt - Universität (Erwachsenenpädagogischer Report, Vol. 6);

Gieseke W. (2005), Vorwort - Kulturelle Bildung in Europa, [w:] W. Gieseke, J. Kargul (red.), Europäisierung durch kulturelle Bildung. Bildung - Praxis - Event, t. 1, Waxman, Münster, s. 13-15.

Gieseke W. (2007), Lebenslanges Lernen und Emotionen. Wirkungen von Emotionen auf Bildungsprozesse aus beziehungstheoretischer Perspektive, Bertelsmann Verlag, Bielefeld.

Gieseke W., Słowińska S., Solarczyk H., Stock H. (2017), The Relationship between Organization of Adults and Further Education and Program Design as illustrated by the Comparative Study on Germany and Poland, [w:] Käpplinger B., Robak S., Fleige M., Von Hippel A., Gieseke W. (red.), Cultures of Program Planning in Adult Education. Concepts, Research Results and Archives, Peter Lang Edition, Frankfurt am Main, s. 113-130.

Gieseke W., Opelt K. (2005), Methodisches Vorgehen der Gesamtuntersuchung, [w:] W. Gieseke, J. Kargul (red.), Kulturelle Erwachsenenbildung in Deutschland. Exemplarische Analyse Berlin/Brandenburg, Münster, s. 39-42.

Gieseke W., Opelt K., Stock H., Börjesson I. (2005), Edukacja kulturalna dorostych w Niemczech. Studium przypadku: Berlin/ Brandenburg, Wyd. ITEE, Warszawa-Płock.

Käpplinger B., Robak S., Fleige M., Von Hippel A., Gieseke W. (red.) (2017), Cultures of Program Planning in Adult Education. Concepts, research Results and Archives, Peter Lamg Verlag, Frankfurt a/M.

Kargul J., Börjesson I. (2005), Interkulturelle Forschungsprämissen und Methoden (Vorgehensweise, getrennte Untersuchungen, Gegensatzadäquanz), [w:] Deutsch-polnische Forschungsgruppe (red.), Interkulturelle Betrachtungen kultureller Bildung in Grenzregionen - mit Buckower Empfehlungen, Humboldt Universität zu Berlin, s. 26-32.

Kargul J., Słowińska S., Gancarz M. (2004), Z prądem i pod prąd. Lubuskie instytucje kultury w nowym ładzie społecznym, Wyd. Uniwersytetu Zielonogórskiego, Zielona Góra.

Krajewski M., Schmidt F. (2014), Animacja/edukacja. Możliwości i ograniczenia edukacji i animacji kulturowej w Polsce. Raport z pierwszego etapu badań, Małopolski Instytut Kultury, Kraków, http://badania-w-kulturze.mik.krakow.pl/files/animacja_edukacja.pdf (20.01.2018).

Nuissl E., Przybylska E. (2015), Kulturvermittlung im öffentlichen Raum am Beispiel von Museen, „Rocznik Andragogiczny“.

Nuissl E., Przybylska E. (2017), Kultur aneignen. Vom Erlernen kultureller Identizität, Schneider Verlag, Hohengehren. 
Słowińska S. (2007), Edukacja kulturalna w Polsce i w Niemczech. Inspiracje - propozycje, koncepcje, Wyd. Impuls, Kraków.

Słowińska S. (red.) (2015), Inicjatywy angażujace osoby 50+ jako przestrzeń indywidualnego rozwoju i kształtowania kapitału społecznego, Oficyna Wydawnicza Uniwersytetu Zielonogórskiego, Zielona Góra.

Słowińska S. i in. (2012), Inicjatywy i ludzie w kulturze lubuskiej - nowe przestrzenie. Raport z badań, Zielona Góra, http://www.inicjatywyiludzie.wpps.uz.zgora.pl/ /raport.pdf (20.01.2018).

Słowińska S. (2016), Marion Fleige, Wiltuud Gieseke, Steffi Robak, Kulturelle Erwachsenenbildung: Strukturen - Partizipationsformen - Domänen (recenzja), „Rocznik Andragogiczny“, s. 393-396.

Słowińska S. (2017), Sensy oddolnych inicjatyw kulturalnych $w$ interpretacji ich realizatorów, Oficyna Wydawnicza UZ, Zielona Góra.

Stock H. (2005), Sparten. Orte für kulturelle Bildung? Weiterbildung in Berlin und Brandenburg, [w:] W. Gieseke, J. Kargul (red.), Kulturelle Erwachsenenbildung in Deutschland. Exemplarische Analyse Berlin/Brandenburg, Münster, s. 263-316 .

Szumski G. (2006), Integracyjne kształcenie niepełnosprawnych. Sens i granice zmiany edukacyjnej, PWN, Warszawa.

Tönnis F. (1985), Wspólnota i stowarzyszenie, PWN, Warszawa.

Welsch W., Transculturality - the Puzzling Form of Cultures Today, w: Featherstone M., Lash S. (eds.), Spaces of Culture: City, Nation, World, London: Sage 1999, p. 194-213, http://web.archive.org/web/20140714152831/http://www2.uni-jena.de /welsch/Papers/transcultSociety.html [dostęp: 06.04.2018] 